Tema: Solidificação / Lingotamento

\title{
NOVAS TECNOLOGIAS PARA REVESTIMENTO DE PLACAS DE COBRE*
}

\author{
Rafael Oliveira Sena ${ }^{1}$ \\ Marcellus Piedade Silva ${ }^{2}$ \\ Rolf Michael Buttgereit
}

\section{Resumo}

A SMS Siemag tem oferecido ao mercado brasileiro novas tecnologias para Lingotamento Contínuo de Placas com objetivo de aumento de desempenho dos equipamentos. A SMS Siemag tem desenvolvido e otimizado o processo de revestimento de placas de cobre do molde que utiliza em conjunto com o processo de eletrodeposição a tecnologia thermal spray que proporciona um produto com alta propriedade de resistência ao desgaste. O revestimento cerâmico, mais conhecido como UniGuard $^{\mathrm{TM}}$, tem obtido resultados excelentes no mercado da América do Norte atingindo valores superiores a 300.000 toneladas. A utilização do revestimento UniGuard $^{\mathrm{TM}}$ proporciona um aumento de produtividade e redução dos custos de manutenção do molde bem como redução de aquisição de novas placas de cobre. Palavras-chave: Lingotamento contínuo; Molde; Placas de cobre; UniGuard ${ }^{\mathrm{TM}}$.

\section{NEW TECHNOLOGIES FOR COPPER PLATE COATING: UNIGUARD ${ }^{\text {TM }}$ COATING OF SMS SIEMMAG}

\begin{abstract}
SMS Siemag has offered to the Brazilian market new technologies for Continuous Casting Slab with the aim of increasing the performance of equipments. SMS Siemag has developed and optimized the coating process of mould copper plates in conjunction with the electrodeposition process, the thermal spray technology which provides a product with high wear resistance. Ceramic coating, known as UniGuard $^{\mathrm{TM}}$, has achieved excellent results on the North American market reaching values higher than 300,000 tons. The use of UniGuard ${ }^{\mathrm{TM}}$ coating provides an increase of productivity and cost reduction on mould maintenance as well purchase reduction of new copper plates.
\end{abstract}

Keywords: Continuous Casting; Mould; Copper Plates; UniGuard ${ }^{\mathrm{TM}}$.

1 Engenheiro Metalurgista, Graduado Eng. Metalúrgica e de Materiais, Engenheiro de Produto, SMS Siemag, Belo Horizonte, MG, Brasil.

2 Engenheiro Eletricista, Pós Graduado em Gestão de Negócios, Diretor Executivo, SMS Siemag, Belo Horizonte, MG, Brasil.

3 Engenheiro, Graduado na Faculdade de Bochum na Alemanha, Gerente de Operações, SMS Siemag, Belo Horizonte, MG, Brasil.

* Contribuição técnica ao 450 Seminário de Aciaria - Internacional, 25 a 28 de maio de 2014, Porto Alegre, RS, Brasil. 


\section{INTRODUÇÃO}

Revestimentos de placas de cobre são utilizados nos moldes de lingotamento contínuo para diminuir o desgaste e melhorar a qualidade do produto. Cromo e níquel continuam predominantemente sendo utilizados para proteger a superfície das placas de cobre contra desgaste. O recente desenvolvimento de novos processos para revestir placas de cobre de moldes com revestimento cerâmico e/ou ligas metálicas tem proporcionado aos lingotamentos contínuos a oportunidade de melhorar a performance dos moldes. A SMS Siemag tem desenvolvido novos processos de revestimento de placas de cobre utilizando revestimento cerâmico em conjunto com o processo de eletrodeposição para criar um revestimento com excelentes propriedades de resistência ao desgaste, corrosão e resistência térmica. Estudos de casos serão descritos neste trabalho para mostrar como o revestimento UniGuard $^{\mathrm{TM}}$ tem sido capaz de reduzir desgaste do molde, trincas e erosão do menisco, e aumentar a qualidade dos produtos lingotados.

\section{VANTAGENS DA UTILIZAÇÃO DE REVESTIMENTO EM MOLDES}

O Principal objetivo de todo revestimento utilizado em placas de cobre dos moldes de lingotamento é diminuir o desgaste na base do molde. Moldes não revestidos podem gerar problemas de qualidade mais conhecidos como trincas estrelas [1], que são gerados através do arraste de material das placas de cobre e aderência do cobre nas placas de aço. Revestimentos aplicados na região do menisco das placas possuem um efeito de isolamento térmico que permite um melhor desenvolvimento da camada de pó fluxante do molde e tende a promover um perfil térmico mais homogênio na região do menisco. Esses atributos podem ter efeitos positivos na performance do molde e na qualidade do produto [2].

O níquel eletrolítico continua sendo uma ótima opção de revestimento para vários moldes de lingotamento, mas em alguns casos está propicio a fadiga e trincas térmicas na região do menisco. Quando o níquel possui alguns elementos de liga adicionados como cobalto, por exemplo, ou aplicado uma camada superior a 3,0 mm é gerado uma tensão interna excessiva provocando o aparecimento de trincas [3] na região do menisco. Em alguns casos, especialmente na região do menisco, essas trincas propagam para o cobre sendo necessária a remoção das mesmas durante processo de recuperação diminuindo assim a vida útil da placa de cobre. Para lingotamentos CSP® e outros com altas velocidades de lingotamento a utilização de níquel eletrodepositado não é bem sucedido porque o níquel tende a trincar severamente e lascar após poucas corridas. O revestimento de níquel e o revestimento de níquel com adições de ligas possuem uma espessura limite a ser aplicada na região do menisco e para alguns casos sua utilização é inviável. As Figuras 1 e 2 mostram o aparecimento de trincas na região do menisco em placas com revestimento "full face".

\footnotetext{
* Contribuição técnica ao 450 Seminário de Aciaria - Internacional, 25 a 28 de maio de 2014 Porto Alegre, RS, Brasil.
} 

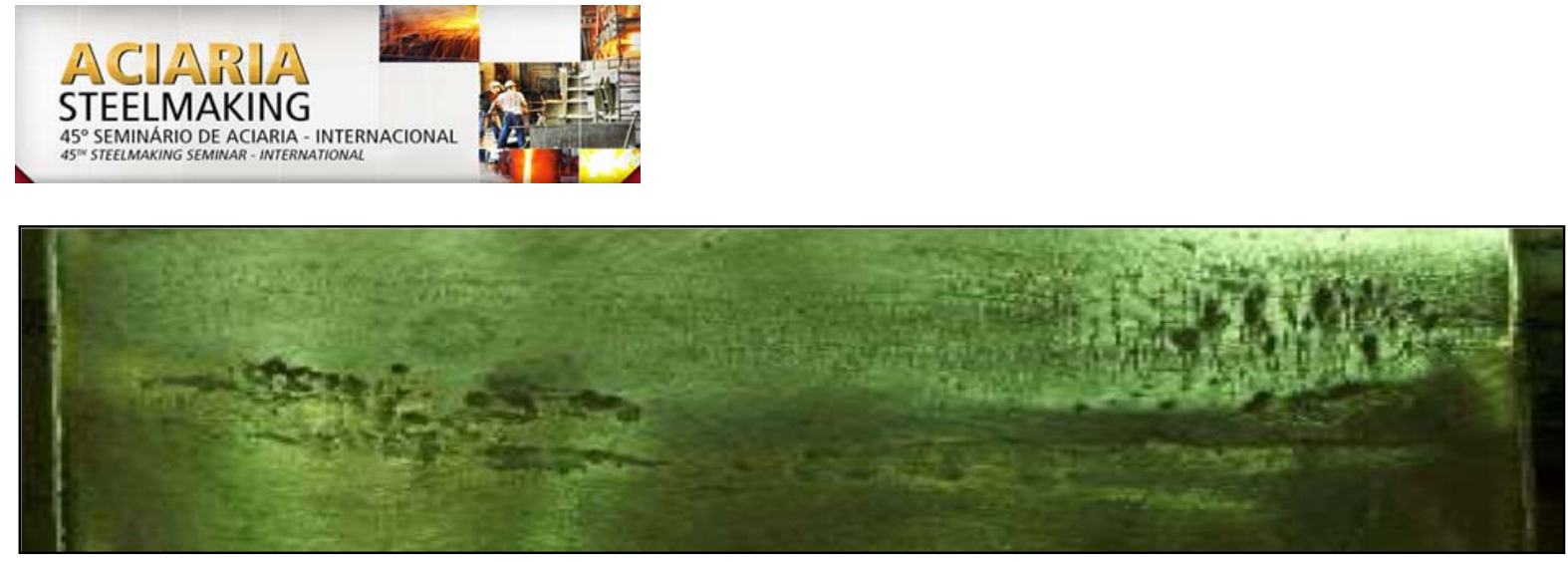

Figura 1. Trincas e lascamento na região do menisco de uma placa estreita.

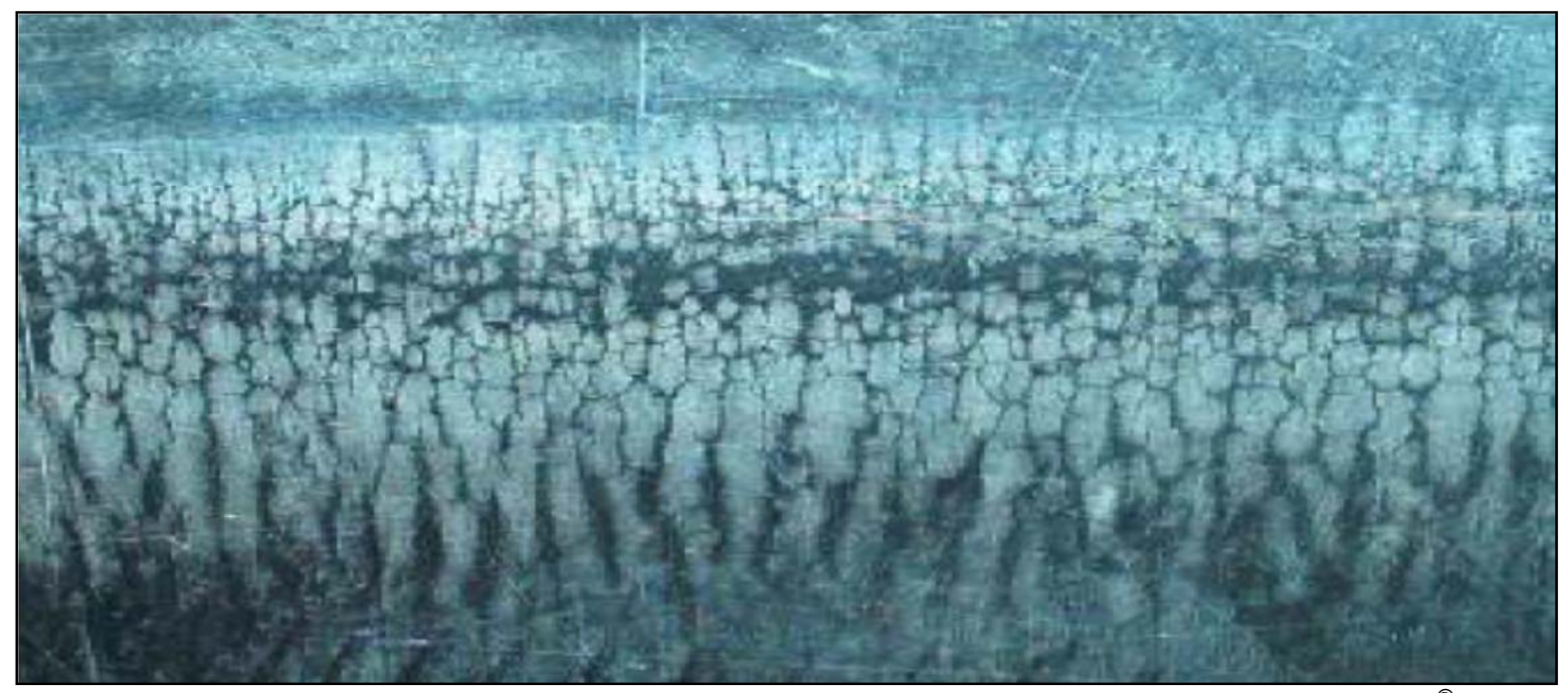

Figura 2. Trincas térmicas na região do menisco de uma placa larga, Lingotamento CSP ${ }^{\circledR}$.

As máquinas de lingotamento contínuo têm tentado estender o período entre manutenção dos moldes, mas as placas estreitas tem sido um fator limitante. $O$ desgaste das placas estreitas é superior ao desgaste das placas largas, possuindo aproximadamente metade da vida do revestimento em comparação com as placas largas. O desgaste das placas estreitas frequentemente ocorre na região inferior chegando a valores $6,5 \mathrm{~mm}$ de desgaste. Em média, o desgaste na região inferior das placas estreitas é em torno de 2,0 a 2,5 mm. Essas cavidades formadas nas quinas devido ao desgaste das placas de cobre podem marcar as placas de aço produzidas e em alguns casos ocasionar break outs devido ao rompimento da camada de pele solidificada. A Figura 3 exemplifica o desgaste nas placas estreitas conforme mencionado acima.

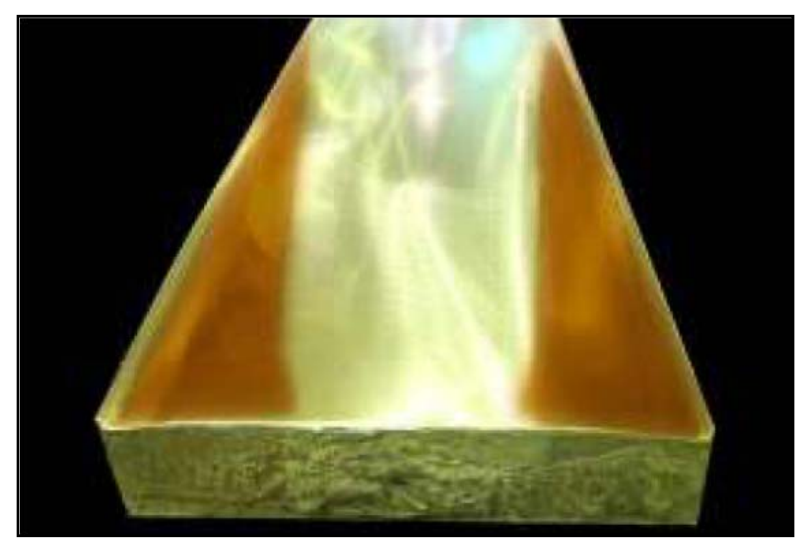

Figura 3. Típico desgaste nas placas estreitas.

\footnotetext{
* Contribuição técnica ao 450 Seminário de Aciaria - Internacional, 25 a 28 de maio de 2014, Porto Alegre, RS, Brasil.
} 


\section{VANTAGENS DA UTILIZAÇÃO DO REVESTIMENTO UNIGUARD ${ }^{\mathrm{TM}}$}

A principal vantagem da utilização do revestimento UniGuard ${ }^{\mathrm{TM}}$ em placas de cobre é a redução de desgaste. Em vários casos de placas de cobre revestidas com revestimento UniGuard ${ }^{\mathrm{TM}}$ usadas de 2 a 3 vezes com o mesmo tempo de uso do revestimento convencional de níquel, apresentaram um desgaste de apenas 0,1-0,3 mm. Este mínimo desgaste das placas de cobre significa que a qualidade das placas de aço produzidas não será afetada pelo pick up de cobre e menos remoção de cobre será necessária durante recuperação. $O$ taper do molde se mantém consistente ao longo das campanhas ao contrário quando se utiliza revestimento de níquel onde ocorre perda de taper devido desgaste. A configuração "full face" do revestimento UniGuard ${ }^{\mathrm{TM}}$ também protege a região do menisco dos ciclos térmicos e dos ataques de zinco, cádmio e outros elementos que flutuam na região do menisco.

Outros benefícios oferecidos pelo revestimento UniGuard ${ }^{\mathrm{TM}}$ são a manutenção do formato do molde, consequentemente diminuição dos desvios dimensionais das placas de aço, diminuição dos chamados corner gaps entre a placa larga e placa estreita e diminuição de arranhões na parte superior das placas de cobre mesmo em campanhas bastante longas.

O sucesso do revestimento UniGuard ${ }^{\mathrm{TM}}$ está nas suas características de dureza e resistência ao ciclo térmico e a não necessidade de alterações nos parâmetros de processo do lingotamento contínuo. A relação da taxa de transferência de calor entre níquel e UniGuard ${ }^{\mathrm{TM}}$ é aproximadamente 5:1, e a relação entre cobre e UniGuard ${ }^{\mathrm{TM}}$ é 30:1. Essa característica de transferência térmica possibilita a utilização de placas já sucatadas que não poderiam ser utilizadas com revestimento convencional de níquel e a redução da espessura do cobre durante a aquisição de novas placas de cobre. O acabamento superficial do revestimento é texturizado e consideravelmente mais rugoso em comparação com níquel convencional. O revestimento UniGuard ${ }^{\mathrm{TM}}$ possui uma resistência á abrasão superior aos demais revestimentos. O fator "taber" de abrasão mostrado na Tabela 1 foi obtido seguindo um teste padrão "10000-cycle Taber abrasion test" que é uma referência quantitativa para teste de resistência ao desgaste.

Tabela 1. Comparação das propriedades físicas entre UniGuard ${ }^{\mathrm{TM}}$ e níquel eletrodepositado $[3,4]$

\begin{tabular}{|c|c|c|c|}
\cline { 3 - 4 } \multicolumn{2}{c|}{} & UniGuard & Níquel $^{\mathrm{TM}}$ \\
\hline Transferência de Calor & $\mathrm{kcal} / \mathrm{m} / \mathrm{hr} / \mathrm{C}$ & 11 & 55 \\
\hline Dureza & $\mathrm{HV}$ & $1150-1250$ & $175-250$ \\
\hline Rugosidade & $\mathrm{RMS}$ & $125-175$ & $16-32$ \\
\hline Tensão interna & $\mathrm{N} / \mathrm{mm}^{2}$ & Menor que 10 & $10-80$ \\
\hline Resistência ao Desgaste & Taber Factor & 4.6 & 6.4 \\
\hline Resistência ao Impacto & - & Moderado & Bom \\
\hline
\end{tabular}

\section{ESTUDOS DE CASOS}

\subsection{ArcelorMittal Cleveland - Cleveland, OH}

Os primeiros testes na usina ISG Cleveland, nos Estados Unidos, aconteceram em meados de 2002 com foco em aumento da vida útil das placas de cobre estreitas. $O$ revestimento de níquel possuía configuração "full face tapered" e apresentava desgaste excessivo após 100.000 - 125.000 toneladas lingotadas com necessidade de serem substituídas em comparação com as placas largas numa relação de 2:1.

* Contribuição técnica ao 450 Seminário de Aciaria - Internacional, 25 a 28 de maio de 2014, Porto Alegre, RS, Brasil. 


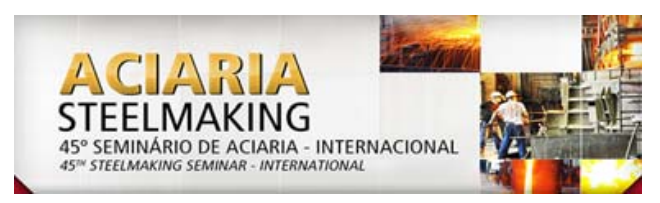

As placas largas possuíam um desgaste bastante acentuado se tornando uma preocupação após 150.000-170.000 toneladas. Foi desenvolvido uma configuração de revestimento UniGuard ${ }^{\mathrm{TM}}$ mantendo as mesmas características de extração de calor atingidas pelo revestimento convencional de níquel. Os primeiros testes apresentaram excelentes resultados dobrando a vida em relação ao revestimento convencional de níquel, com campanhas excedendo 300.000 toneladas lingotadas. Em 2004 algumas mudanças adicionais na configuração do revestimento foram realizadas para prolongar a vida do molde atingindo valores acima de 500.000 toneladas. Em 2005 foram retirados de operação três moldes que ultrapassaram uma vida de 500.000 toneladas.

Moldes não são removidos mais por desgaste das placas de cobre, mas por "corner gaps" ou necessidade de manutenção elétrica ou mecânica. Em 2006 foi retirado um molde de operação que atingiu um recorde de 586.913 toneladas lingotadas. A redução de custos associado com a extensão da campanha do molde foram notáveis. Estimativas conservadoras tem mostrado redução no custo de manutenção de moldes pela metade na MLC\#01 da ArcelorMlttal Cleveland.

$\mathrm{O}$ desgaste nas placas largas com revestimento UniGuard ${ }^{\mathrm{TM}}$ após 300.000 400.000 toneladas apresentam normamente um desgaste inferior a 0,25 mm. A significativa redução de desgaste nas placas largas retarda o aparecimento de "corner gaps" e mantém a geometria do molde após campanhas bastante extensas. As Figuras 4 a 7 mostram fotos comparativas dos revestimentos convencionais de níquel e UniGuard ${ }^{\mathrm{TM}}$ com seus respectivos aspectos de desgaste.

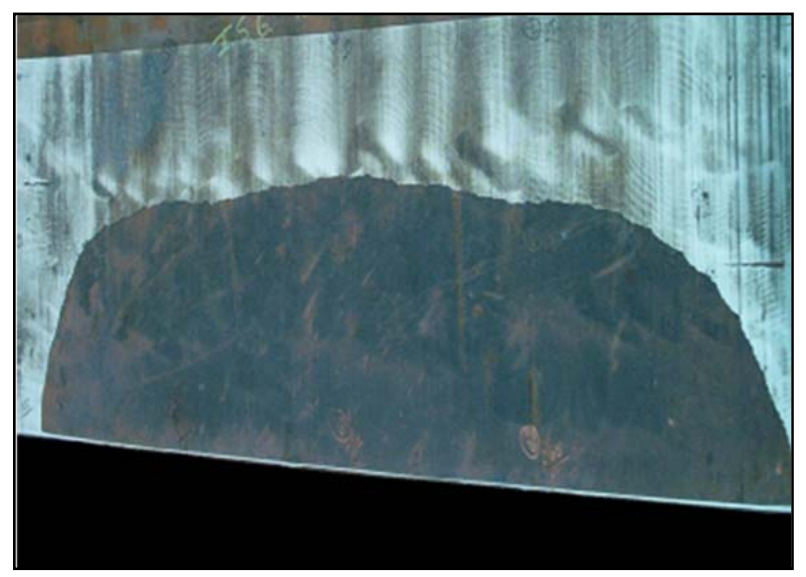

Figura 4. Placa Larga com revestimento de Ni após 150.000 toneladas.

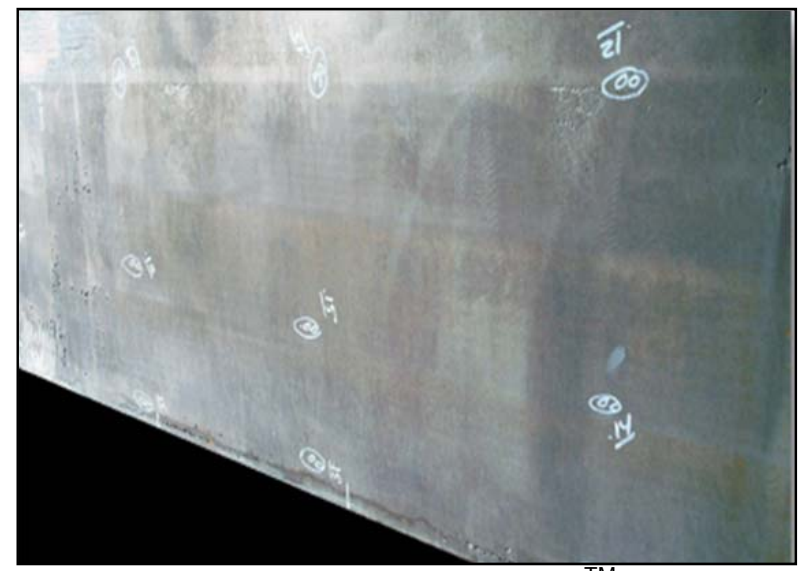

Figura 5. Placa Larga com revestimento UniGuard ${ }^{\mathrm{TM}}$ após 389.000 toneladas.

\footnotetext{
* Contribuição técnica ao 450 Seminário de Aciaria - Internacional, 25 a 28 de maio de 2014, Porto Alegre, RS, Brasil.
} 

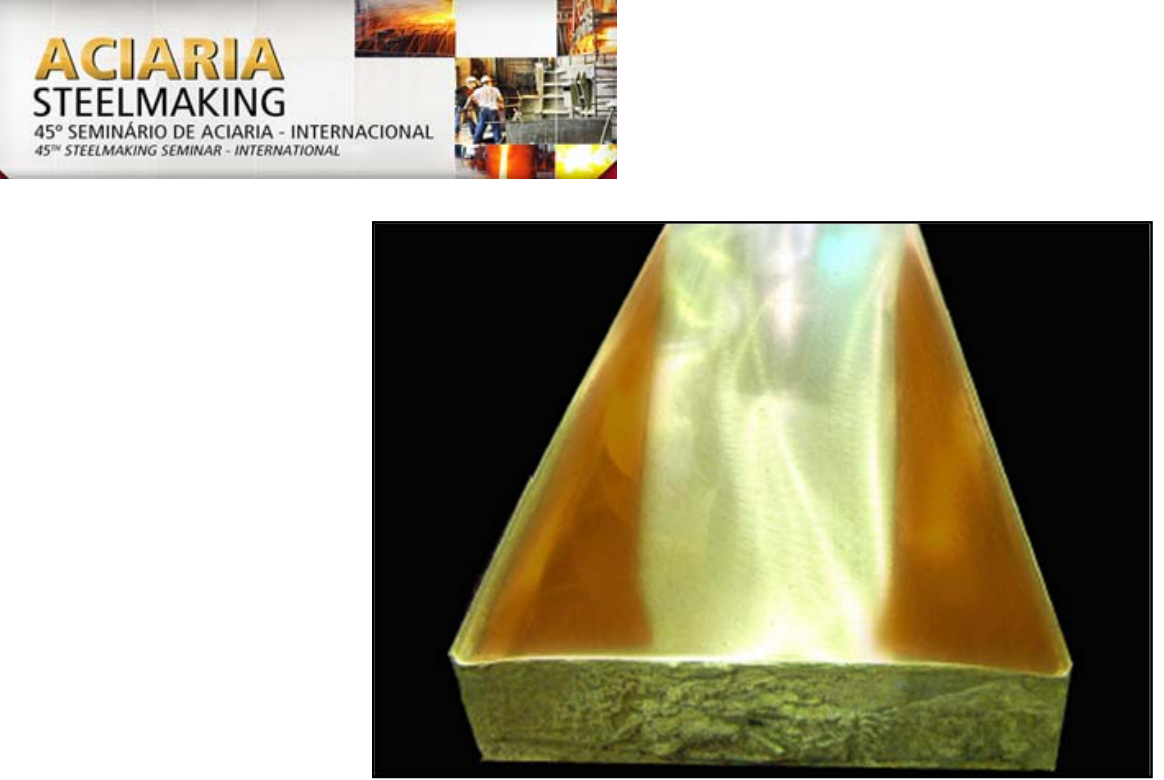

Figura 6. Placa estreita com revestimento de Ni após 125.000 toneladas e desgaste de 3,0 mm.

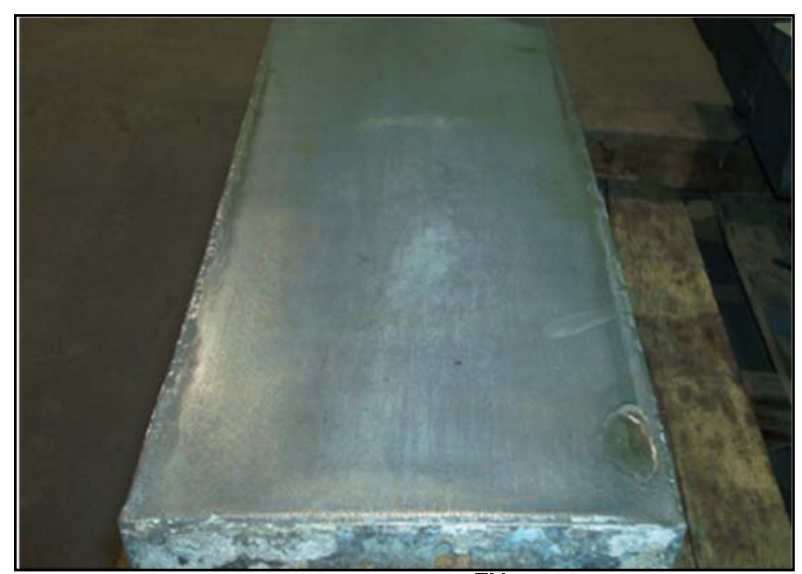

Figura 7. Placa Larga com revestimento UniGuard ${ }^{\mathrm{TM}}$ após 500.000 toneladas e desgaste de $0,25 \mathrm{~mm}$.

Uma vantagem adicional como resultado do aumento da campanha dos moldes, é o aumento da disponibilidade de sobressalentes e redução de aquisição de novas placas de cobre devido à diminuição de desgaste acarretando menor remoção de cobre durante recuperações. A redução de custos com aumento do número de campanhas dos moldes tem sido suficiente para justificar a utilização do revestimento UniGuard $^{\mathrm{TM}}$. A Figura 8 mostra a remoção média de cobre das placas estreitas durante a recuperação com revestimento UniGuard ${ }^{\mathrm{TM}}$ e observa-se metade de redução em comparação com revestimento convencional de níquel.

* Contribuição técnica ao 450 Seminário de Aciaria - Internacional, 25 a 28 de maio de 2014, Porto Alegre, RS, Brasil. 


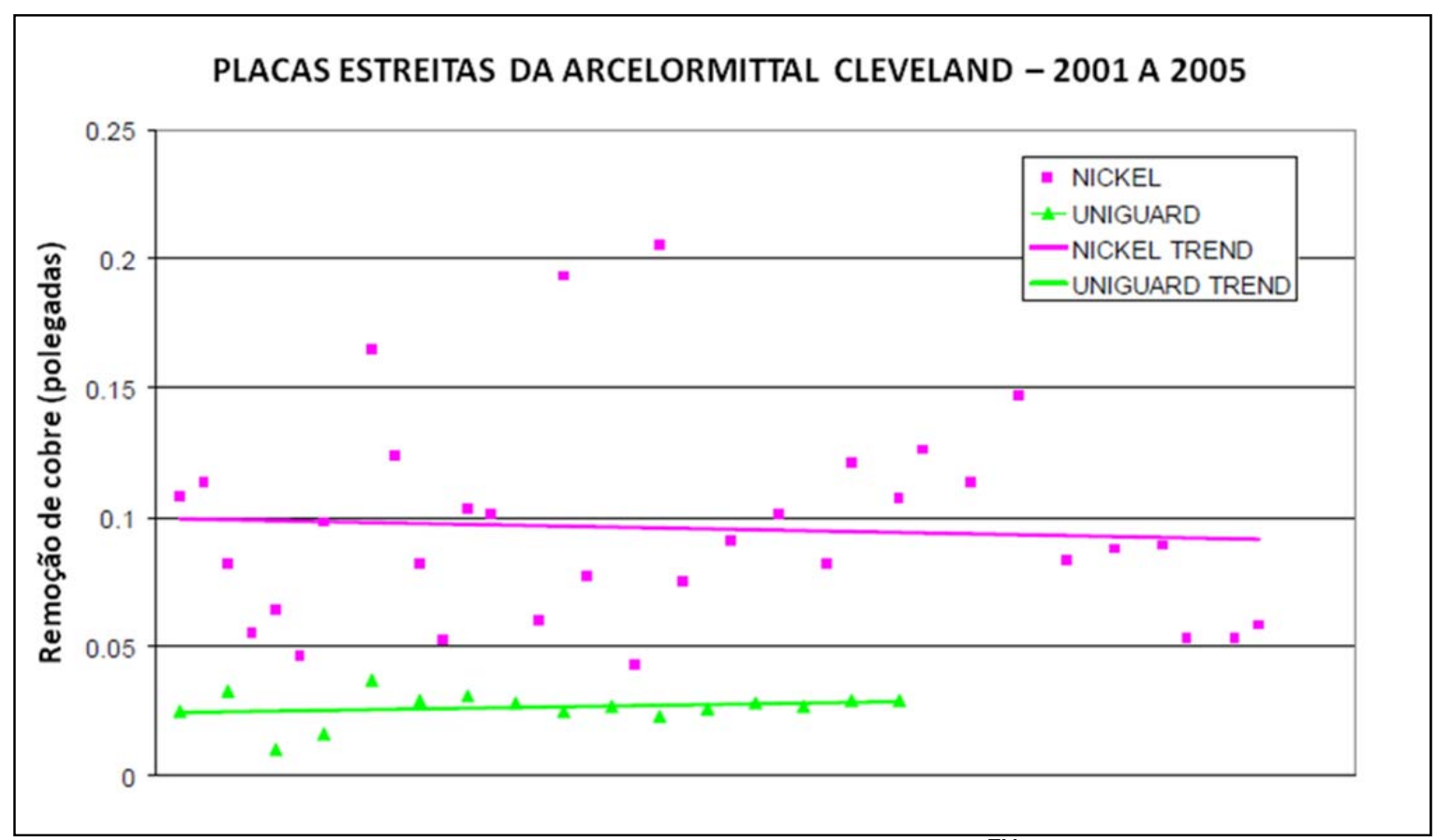

Figura 8. Remoção de cobre por campanha, UniGuard ${ }^{\mathrm{TM}}$ versus Níquel.

Com os excelentes resultados obtidos, o cliente adotou o revestimento UniGuard ${ }^{\mathrm{TM}}$ como revestimento padrão e desde então tem reduzido custos de manutenção de moldes e aquisição de novas placas de cobre.

\subsection{IPSCO Alabama - Mobile, AL}

Durante start up do Lingotamento para produção de placas para aplicação de chapas grossas em 2001, foram rapidamente identificados sérios problemas de desgaste que não haviam sido identificados pela maioria dos lingotamentos contínuos. A gerência da planta de IPSCO verificou e decidiu rapidamente que os sérios problemas de desgaste não poderiam ser resolvidos utilizando o revestimento convencional de níquel. Depois de 200.000 toneladas as placas de cobre estreitas apresentavam desgaste superior a $1,5 \mathrm{~mm}$. As placas largas também apresentavam desgastes excessivos principalmente onde as placas estreitas eram posicionadas provocando severas marcas nas placas, como pode ser visto na Figura 9. Essas marcas apresentavam desgaste de $1,5 \mathrm{~mm}$ após apenas 35.000 toneladas. Em 2003, após implementação do revestimento UniGuard ${ }^{\mathrm{TM}}$ as placas largas e as placas estreitas apresentaram um desgaste bastante inferior atingindo campanhas até 275.00 toneladas [5].

Melhorias contínuas tem sido realizadas na utilização do revestimento UniGuard ${ }^{\mathrm{TM}}$ pela usina de IPSCO e pequenos ajustes na configuração do revestimento tem aumentado a campanha dos moldes. Em 2005 foi atingido um recorde de 384.296 toneladas lingatoadas (2,140 corridas). Mesmo após o recorde alcançado o desgaste atingido foi menor que $0,25 \mathrm{~mm}$ e observado onde ocorriam várias marcas, devido ao contato das placas estreitas, o desgaste foi de apenas 0,4-0,5 mm.

\footnotetext{
* Contribuição técnica ao 450 Seminário de Aciaria - Internacional, 25 a 28 de maio de 2014, Porto Alegre, RS, Brasil.
} 

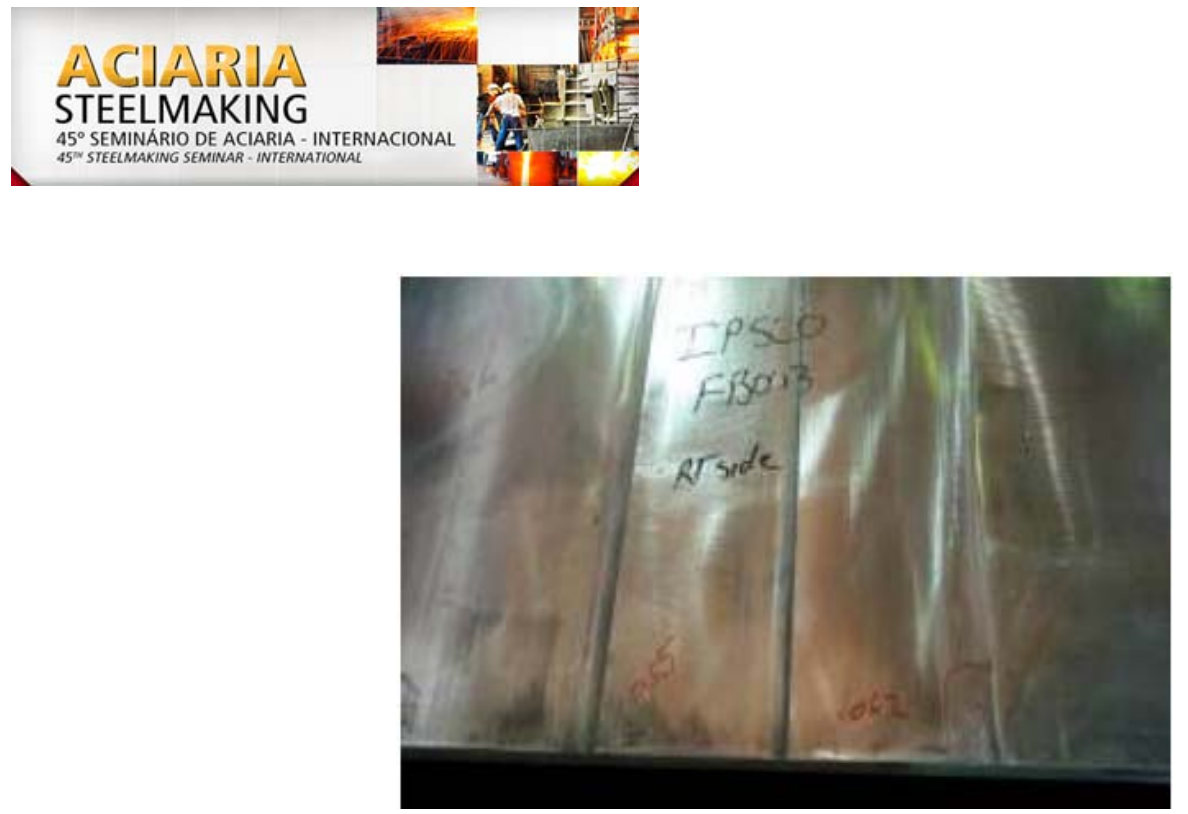

Figura 9. Placa Larga com revestimento de Ni após 35.000 toneladas.

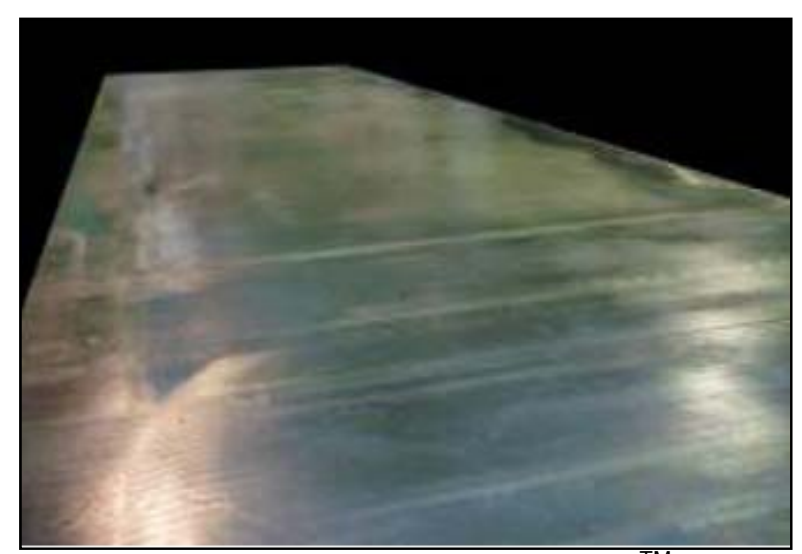

Figura 10. Placa Larga com revestimento UniGuard ${ }^{\text {TM }}$ após 384.296 toneladas.

Redução de custos com a utilização do revestimento UniGuard ${ }^{\mathrm{TM}}$ em IPSCO Alabama tem sido impressionantes, não apenas pelo aumento da campanha dos moldes mas também pela menor quantidade de material removido durante recuperação das placas de cobre prolongando a vida total das mesmas. O mais importante é que se obteve um impacto positivo na qualidade dos produtos lingotados devido manutenção da geometria do molde e uma extração de calor mais consistente na região do menisco.

\subsection{Testes com Revestimento UniGuard ${ }^{\mathrm{TM}}$ no Brasil}

A SMS Siemag tem ofertado o revestimento UniGuard ${ }^{\text {TM }}$ para o mercado brasileiro e alguns testes estão em andamento. A SMS encontrou certa resistência no início dos projetos e foi necessário apresentação de estudo de elementos finitos para provar que a implantação do revestimento não iria trazer danos ao processo e que grandes mudanças não seriam necessárias. A grande dúvida seria como seria o comportamento térmico na região do menisco, uma vez que o perfil do revestimento UniGuard" $^{\mathrm{TM}}$ é "full face". A SMS Siemag realizou um estudo para um cliente específico no Brasil para mostrar que a alteração de temperatura na região do menisco seria de aproximadamente $40^{\circ} \mathrm{C}$ e que isso não proporcionaria nenhum dano ao processo. A utilização deste revestimento proporciona uma extração de calor mais suave e esse aumento de temperatura na região do menisco é benéfico ao processo. As Figuras 11 e 12 ilustram os resultados obtidos pela simulação

\footnotetext{
* Contribuição técnica ao 450 Seminário de Aciaria - Internacional, 25 a 28 de maio de 2014, Porto Alegre, RS, Brasil.
} 


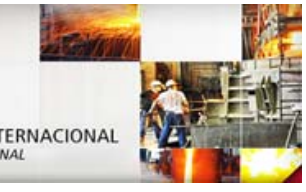

térmica utilizando análise de elementos finitos comparando o revestimento convencional step níquel com revestimento UniGuard" ${ }^{\mathrm{TM}}$ "full face" .

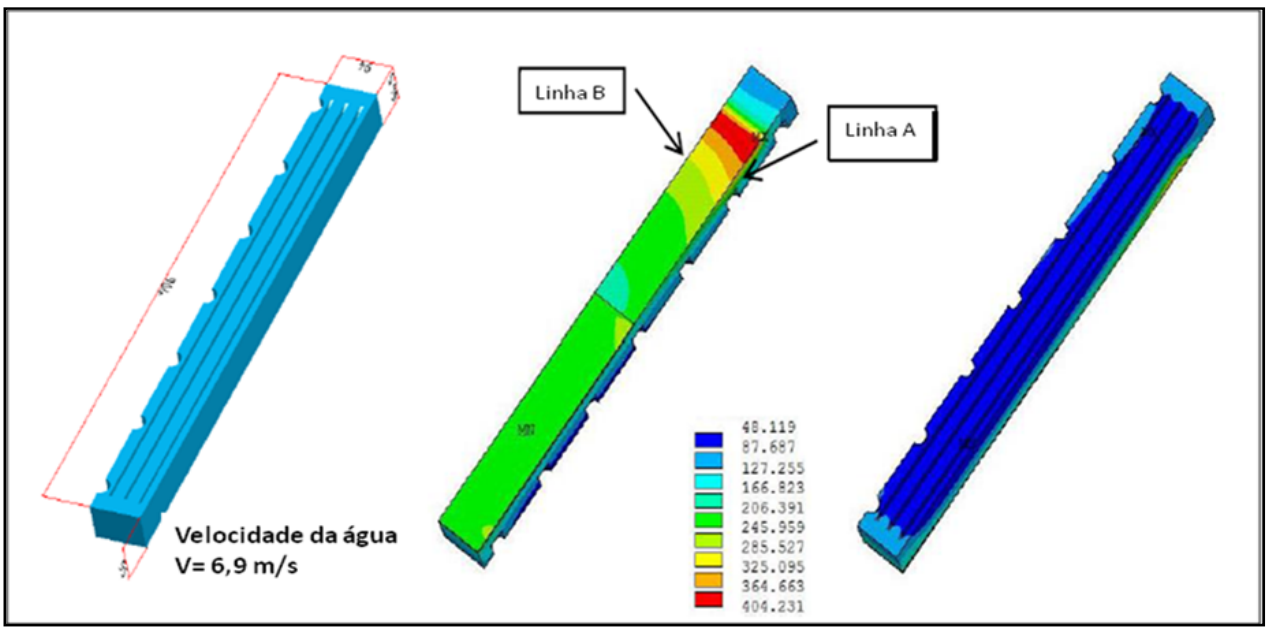

Figura 11. Análise em 3D do perfil de temperatura do revestimento step níquel.

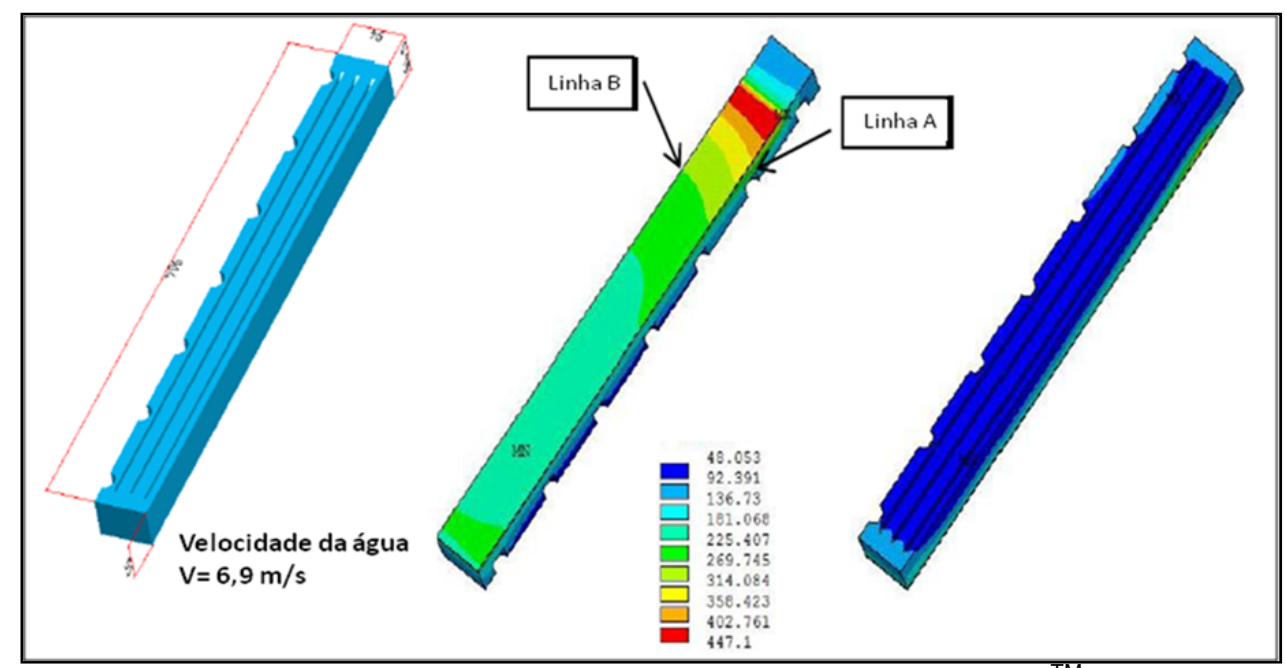

Figura 12. Análise em 3D do perfil de temperatura do revestimento UniGuard" "full face".

Durante testes com revestimento UniGuard ${ }^{\mathrm{TM}}$ em um determinado cliente, foram realizados algumas medições para avaliação do fluxo de calor do molde e verificar a influência do revestimento UniGuard ${ }^{\mathrm{TM}}$ no sistema. Para o cálculo do fluxo utilizou-se os parâmetros de processo como nível do molde, dimensões das placas lingotadas, $\Delta$ temperatura (temperatura de saída - temperatura de entrada) em uma velocidade de lingotamento constante. Conforme observado na Figura 13, a extração de calor no molde revestido com UniGuard ${ }^{\mathrm{TM}}$ não apresentou diferença significativa em comparação com o molde revestido com níquel e nenhum distúrbio no sistema de detecção de alarmes foi detectado.

* Contribuição técnica ao 45 Seminário de Aciaria - Internacional, 25 a 28 de maio de 2014, Porto Alegre, RS, Brasil. 

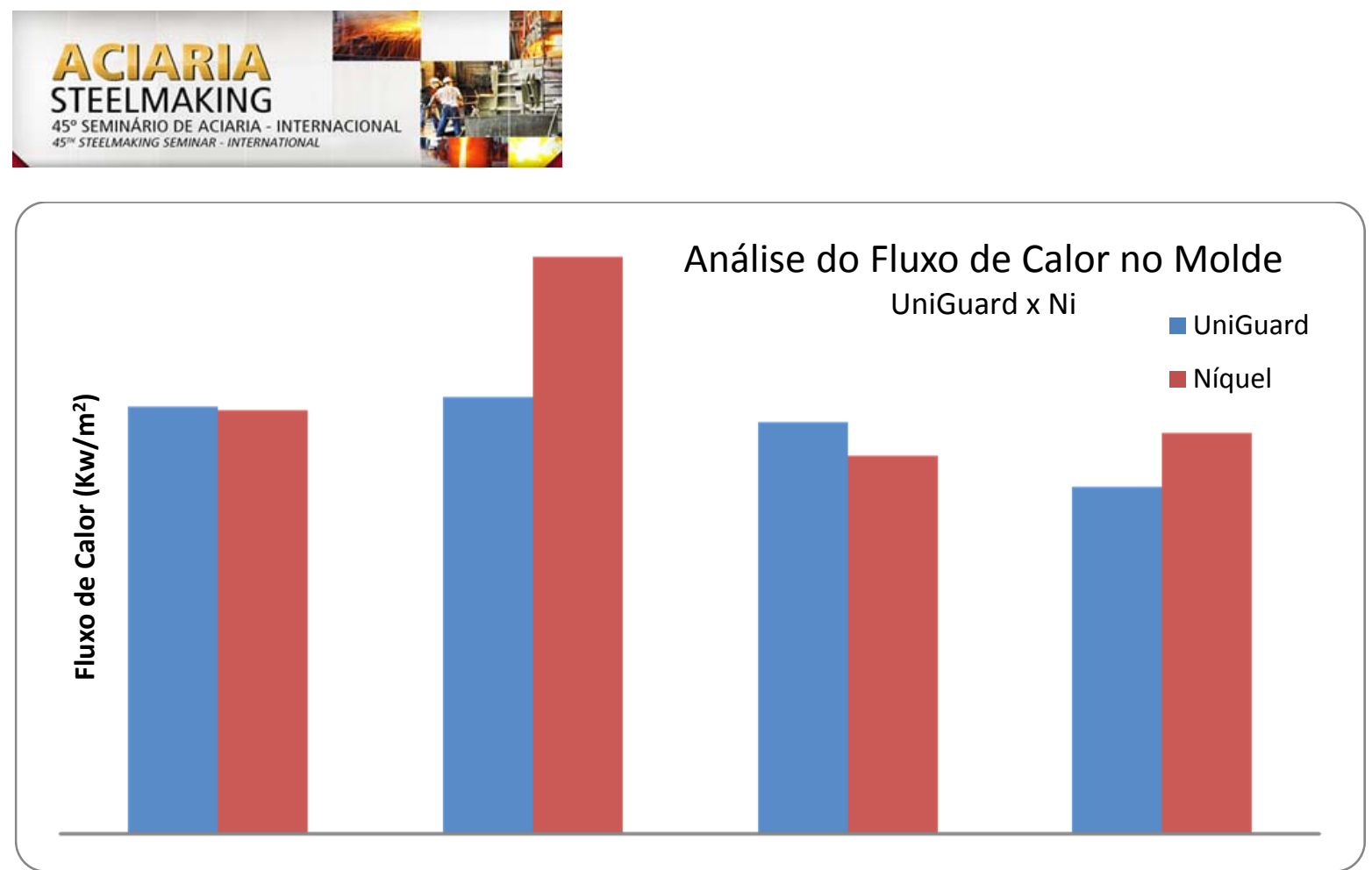

Figura 13. Análise de fluxo de calor no molde UniGuard ${ }^{\mathrm{TM}}$ versus Níquel”.

O revestimento UniGuard ${ }^{\mathrm{TM}}$ está sendo testado nos principais lingotamentos contínuos do Brasil com resultados bastante satisfatórios. Os moldes se encontram em operação e a SMS Siemag tem desenvolvido juntamente com os clientes mecanismos para prolongar a vida do molde bem como entender o comportamento deste novo produto que ajudará as usinas na redução de custos.

\section{ELETRODEPOSIÇÃO DE COBRE}

A SMS Siemag está oferecendo ao mercado brasileiro a eletrodeposição de cobre para recuperação das laterais das placas estreitas que sofrem um desgaste excessivo durante o processo do Lingotamento Contínuo. Esse processo permite que as especificações de projeto das placas de cobre, sejam atendidas durante a recuperação. A especificação de projeto para aplicação da camada de níquel nas laterais das placas de cobre é de $0,5 \mathrm{~mm}$ e normalmente esse valor não é atendido devido às condições severas de desgaste sofrido pelas placas. A utilização de camadas muito espessas de níquel na região lateral das placas de cobre estreitas não é recomendada devido à riscos operacionais. Camadas muito espessas podem gerar uma deformação localizada da placa de cobre proporcionando um gap excessivo na região, podendo gerar infiltração de aço e consequentemente um break out.

A recuperação das placas través do processo de eletrodeposição de cobre proporciona a possibilidade da utilização em placas já sucatadas pela largura e que ainda possuem uma espessura na face quente (face de trabalho) a serem trabalhadas. Esse processo pode diminuir o custo de aquisição de novas placas estreitas. A Figura 14 mostra placa de cobre recuperada com este processo.

\footnotetext{
* Contribuição técnica ao 450 Seminário de Aciaria - Internacional, 25 a 28 de maio de 2014, Porto Alegre, RS, Brasil.
} 

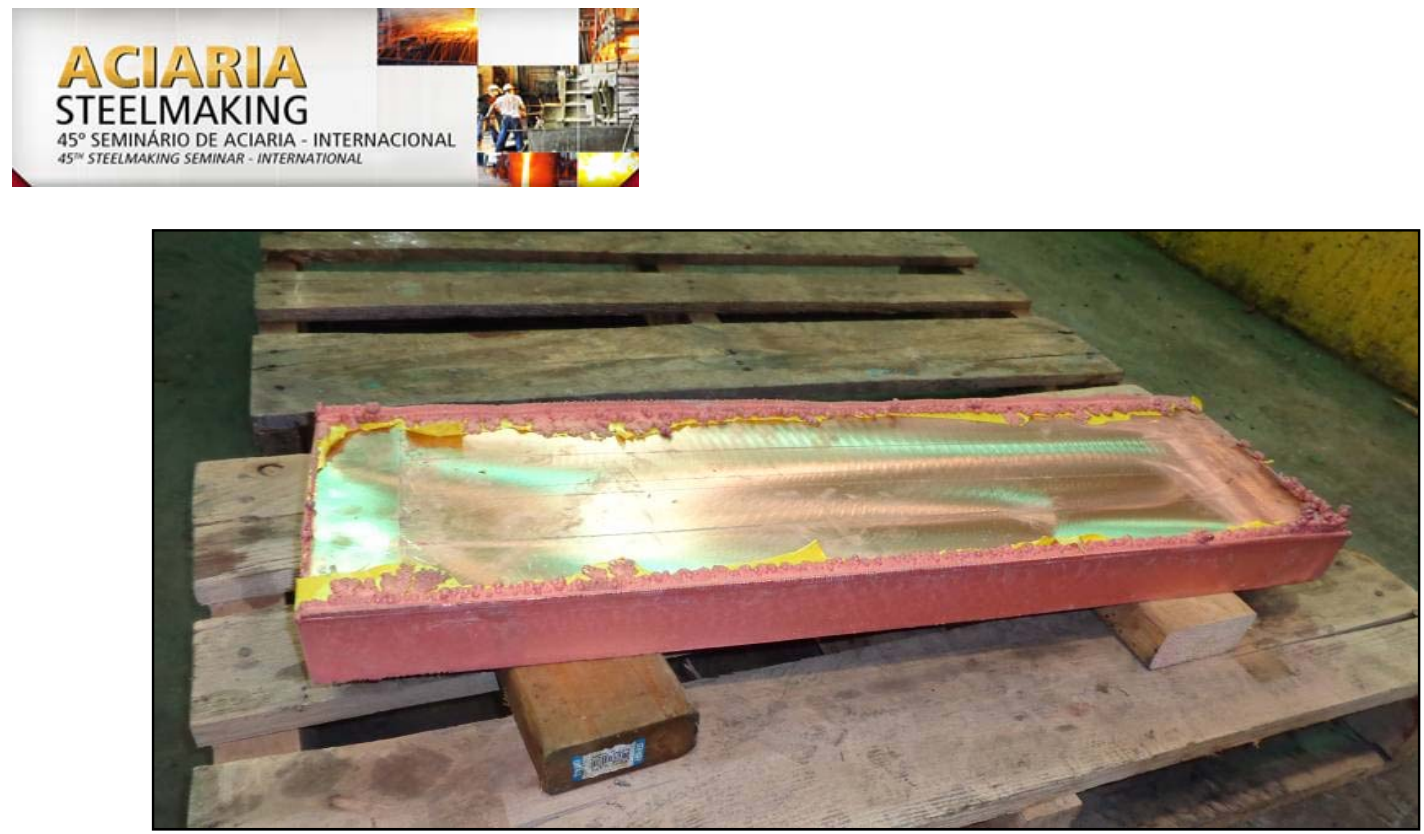

Figura 14. Placa estreita recuperada com eletrodeposição de cobre.

A Tabela 2 mostra as propriedades do cobre eletrodepositado em comparação com a liga $\mathrm{CuCrZr}$. O cobre eletrodepositado, em comparação com a solda de cobre, apresenta muitas vantagens em relação à condutividade dureza e ausência de porosidade.

Tabela 2. Comparação das propriedades mecânicas de uma liga CuCrZr e cobre eletrodepositado

\begin{tabular}{|l|c|c|}
\hline \multicolumn{3}{|c|}{ Propriedades Mecânicas } \\
\hline Cobre & CuCrZr & Cobre Eletrodepositado \\
\hline & - & $99,98 \%$ puro \\
\hline Tensão (KSI) & $54-61$ & - \\
\hline $0,2 \%$ Limite de Escoamento (KSI) & $36-44$ & - \\
\hline Alongamento (\%) & $30-48$ & - \\
\hline Dureza (HB) & $112-130$ & $100-120$ \\
\hline Condutividade Elétrica (\% IAS) & $77-84$ & $95-100$ \\
\hline Condutividade Térmica (BTU/FT-HR ${ }^{\circ}$ F) & 186 & Aproximadamente 200 \\
\hline
\end{tabular}

\section{CONCLUSÃO}

O revestimento UniGuard ${ }^{\mathrm{TM}}$ tem sido utilizado pelos principais Lingotamentos Contínuos da América do Norte e tem proporcionado aos nossos clientes oportunidades de reduções de custos bastantes significativas. A vida média atingida pelo revestimento UniGuard ${ }^{\mathrm{TM}}$ é de aproximadamente 400.000 toneladas e tem proporcionado redução de cerca de $20 \%$ dos custos de manutenção do molde.

O revestimento UniGuard ${ }^{\mathrm{TM}}$ está em operação em algumas máquinas de Lingotamento Contínuo dos nossos clientes brasileiros e acreditamos que iremos atingir os mesmos resultados das usinas americanas. A SMS Siemag está trabalhando no desenvolvimento deste projeto, modificando as configurações dos revestimentos e avaliando o comportamento em cada cliente com objetivo de aumentar a produtividade das máquinas e reduzindo os custos de manutenção dos moldes.

\footnotetext{
* Contribuição técnica ao 450 Seminário de Aciaria - Internacional, 25 a 28 de maio de 2014, Porto Alegre, RS, Brasil.
} 


\section{Agradecimentos}

A SMS Siemag gostaria primeiramente agradecer nossa filial nos EUA, SMS Millcraft que tem nos ajudado a introduzir nosso Revestimento Premium no mercado brasileiro e a desenvolver configurações de revestimentos a serem aplicados em nossos clientes. A SMS Siemag também agradece à USIMINAS e ArcelorMittal Tubarão pela confiança e a oportunidade de desenvolvimento do projeto de um produto novo no mercado que certamente irá proporcionar ganhos consideráveis.

\section{REFERÊNCIAS}

1 Powers JS, Emling WH, Tomazin CE. Refinement of casting parameters for improved surface quality of cold rolled AKDQ sheet. In: ISS Steelmaking Conference Proceedings; 1989, Chicago, EUA. ISS; 1989. p.29-37.

2 Emling WH. Breakout prevention, the making, shaping and treating of steel. 11th Edition Casting Volume. Pittsburgh: The AISE Steel Foundation; 2003. p.1-3.

3 Dennis JK, Such TE. Engineering applications, nickel and chromium plating. $3^{\text {rd }}$ ed. Cambridge: Woodhead Publishing Limited; 1993. p.66-84.

4 Durney LJ. Electroforming, electroplating engineering handbook. London: Chapman \& Hall; 1996. p.480-82.

5 Donovan CB. Recent developments in mold coating technology. In: AIST. AISTech 2004 Proceedings, 2004, Nashville, EUA. Warrendale: AIST; 2004. p.1053-61.

* Contribuição técnica ao $45^{\circ}$ Seminário de Aciaria - Internacional, 25 a 28 de maio de 2014, Porto Alegre, RS, Brasil. 